\title{
Measuring and modeling continuous quality distributions of soil organic matter
}

\author{
S. Bruun ${ }^{1}$, G. I. Ågren ${ }^{2}$, B. T. Christensen ${ }^{3}$, and L. S. Jensen ${ }^{1}$ \\ ${ }^{1}$ Plant and Soil Science Laboratory, Department of Agriculture and Ecology, Faculty of Life Sciences, \\ University of Copenhagen, Thorvaldsensvej 40, 1871 Frederiksberg C, Denmark \\ ${ }^{2}$ Department of Ecology, Swedish University of Agricultural Sciences, P.O. Box 7044, 75007 Uppsala, Sweden \\ ${ }^{3}$ Department of Agroecology and Environment, Faculty of Agricultural Sciences, Aarhus University, 8830 Tjele, Denmark
}

Received: 6 August 2009 - Published in Biogeosciences Discuss.: 15 September 2009

Revised: 26 November 2009 - Accepted: 7 December 2009 - Published: 5 January 2010

\begin{abstract}
An understanding of the dynamics of soil organic matter (SOM) is important for our ability to develop management practices that preserve soil quality and sequester carbon. Most SOM decomposition models represent the heterogeneity of organic matter by a few discrete compartments with different turnover rates, while other models employ a continuous quality distribution. To make the multicompartment models more mechanistic in nature, it has been argued that the compartments should be related to soil fractions actually occurring and having a functional role in the soil. In this paper, we make the case that fractionation methods that can measure continuous quality distributions should be developed, and that the temporal development of these distributions should be incorporated into SOM models. The measured continuous SOM quality distributions should hold valuable information not only for model development, but also for direct interpretation. Measuring continuous distributions requires that the measurements along the quality variable are so frequent that the distribution approaches the underlying continuum. Continuous distributions lead to possible simplifications of the model formulations, which considerably reduce the number of parameters needed to describe SOM turnover. A general framework for SOM models representing SOM across measurable quality distributions is presented and simplifications for specific situations are discussed. Finally, methods that have been used or have the potential to be used to measure continuous quality SOM distributions are reviewed. Generally, existing fractionation methods will have to be modified to allow measurement of distributions or new fractionation techniques will have to be devel-
\end{abstract}

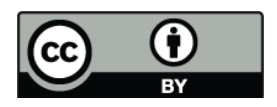

Correspondence to: S. Bruun (sab@life.ku.dk) oped. Developing the distributional models in concert with the fractionation methods to measure the distributions will be a major task. We hope the current paper will help generate the interest needed to accommodate this.

\section{Introduction}

Understanding the dynamics of soil organic matter (SOM) and mechanisms that stabilize organic matter in soil is important for our ability to develop management practices that preserve soil quality and sequester carbon. Most SOM models are multi-compartment models describing organic matter turnover as the consequence of transformations between different compartments of different decomposability or biological quality (McGill, 1996; Coleman and Jenkinson, 1996; Parton et al., 1987; Reichstein et al., 2009). However, these model compartments are unrelated to measurable entities. This means that the pools and flows between them are largely theoretical constructs introduced to mimic the heterogeneity of SOM and are not inferred from direct evidence of their existence. To make multi-compartment models more mechanistic, it has been argued that their pools should correspond to measurable SOM fractions having a functional role in the soil (Hassink, 1995; Christensen, 1996; Elliott et al., 1996; Balesdent, 1996; Arah and Gaunt, 2001; Smith et al., 2002; von Lützow et al., 2007). The basis for validation of a multi-compartment model is much improved when measurable SOM fractions are used because the model can be tested for its ability to simulate the amount of $\mathrm{C}$ and isotopic ratios in each SOM fraction. In addition, the measurable SOM fractions provide information that may help distinguish and disentangle the different mechanisms responsible for the

Published by Copernicus Publications on behalf of the European Geosciences Union. 
stabilization of SOM. As a result of these theoretical developments, procedures to obtain fractions that are more uniform with respect to molecular composition or physical protection, and that are therefore more suitable as model pools, have been developed (Hassink, 1995; Trumbore and Zheng, 1996; Magid et al., 1996; Six et al., 1998; Sohi et al., 2001; Christensen, 2001). Successful attempts have been made to base models on measurable SOM fractions (Buyanovsky et al., 1994; Hassink and Dalenberg, 1996; Bird et al., 2002; Baisden and Amundson, 2003; Skjemstad et al., 2004, Zimmermann et al., 2007). However, the envisaged impact of measurable SOM fractions on SOM models has as yet only materialized to a modest degree.

The number of different chemical constituents in SOM is extremely large and the SOM is protected from degradation by a multitude of mechanisms (Sollins et al., 1996; von Lützow et al., 2006). Therefore, the decomposability or quality of SOM is better described as a continuum than as a number of separate compartments. Even a relatively well defined SOM fraction, such as black carbon, is more appropriately characterized as a continuum, ranging from slightly charred biomass to soot and graphite (Goldberg, 1985; Masiello, 2004). Therefore, the idea of representing the quality of SOM as a continuous quality distribution is obvious, and several models have been developed, based on this concept (Bosatta and Ågren, 1985; Ågren et al., 1996b). In their general form, they make very few simplifying assumptions. However, the definitions of the quality distributions are as unrelated to anything measurable as the compartments of the multi-compartment models.

We argue that rather than fractionating the SOM into a few operationally defined fractions or defining quality distributions that are not related to anything measurable, it may be feasible to develop methods to measure the continuous quality distributions of SOM and incorporate these into continuous quality distribution SOM models. The quality will then be represented by some measurable variable such as particle size, particle density or resistance of SOM to oxidation. The methods used to measure SOM fractions in soil will generally have to be modified to enable measurement of continuous quality distributions, or rather new techniques will need to be developed and applied. The objectives of the current paper are to discuss the implications of characterizing SOM by continuous quality distributions, present a possible modeling framework that can be used to model the measured continuous quality SOM distributions and review methods that can be employed to measure the distributions.

\section{Models of measurable continuous quality distributions of SOM}

SOM models with continuous quality distributions were originally suggested by Carpenter (1981). Later, the models and concepts upon which they are based were greatly ex- panded (Bosatta and Ågren, 1985, 1991, 2003, Ågren and Bosatta, 1996a, b). Boudreau (1992) developed a model based on similar arguments for organic matter in marine sediments.

Several model formulations incorporating measurable continuous quality distributions can be envisaged. In this paper we present an example of a one-dimensional continuous distribution model and suggest possible simplifications, extensions and generalizations that could be appropriate in different situations.

\subsection{One-dimensional continuous distribution model}

To obtain a model that represents the soil organic carbon (SOC) by a one-dimensional quality distribution, we introduce a variable $q$ that represents the quality of SOC. This variable is determined by the fractionation method used to measure the distribution of SOM qualities. It may be any of the variables suggested later such as size, density, or resistance to oxidation. At time $t$, we assume that there exists a continuous distribution of SOC, $\rho(q, t)$, defined such that $\rho(q, t) d q$ is the amount of SOC in the quality interval $q$ to $q+d q$. The total amount of SOC in the soil can thus be found by:

$C(t)=\int_{-\infty}^{\infty} \rho(q, t) d q$

If we assume that this distribution changes in time as a consequence of external inputs $(I(q, t))$, respiration $(R(q, t))$, and modifications of the quality in time $\left(M\left(q, q^{\prime}, t\right)\right)$, the time derivative is:

$\frac{\partial \rho(q, t)}{\partial t}=I(q, t)-R(q, t)+\int_{-\infty}^{\infty} M\left(q, q^{\prime}, t\right) d q^{\prime}$

where $M\left(q, q^{\prime}, t\right)$ is a distributional kernel which defines the rate at which SOC is moved from quality $q^{\prime}$ to $q$. Conservation of mass dictates that $\int_{-\infty}^{\infty} \int_{-\infty}^{\infty} M\left(q, q^{\prime}\right) d q^{\prime} d q=0$. The inclusion of $t$ as a variable in $R(q, t)$ and $M\left(q, q^{\prime}, t\right)$ indicates that these function can depend on other factors, such as temperature, that may vary in time. The temporal development of the distribution from time $t$ to $t+d t$ is illustrated in Fig. 1 .

What remains to make the model functional is to assume some dependencies and functional forms of $R(q, t)$ and $M\left(q, q^{\prime}, t\right)$. A reasonable simplifying assumption is that respiration is proportional to the amounts of carbon of different qualities, i.e. the respiration rate is equal to $k(q, t) \rho(q, t)$, where $k(q, t)$ is a specific respiration function dependent on the quality. Another simplifying assumption could be to describe the transformations between qualities as a flux, $F(q, t)$, along the $q$-axis. The model reduces then to:

$\frac{\partial \rho(q, t)}{\partial t}=I(q, t)-k(q, t) \rho(q, t)+\frac{\partial F(q, t)}{\partial q}$ 


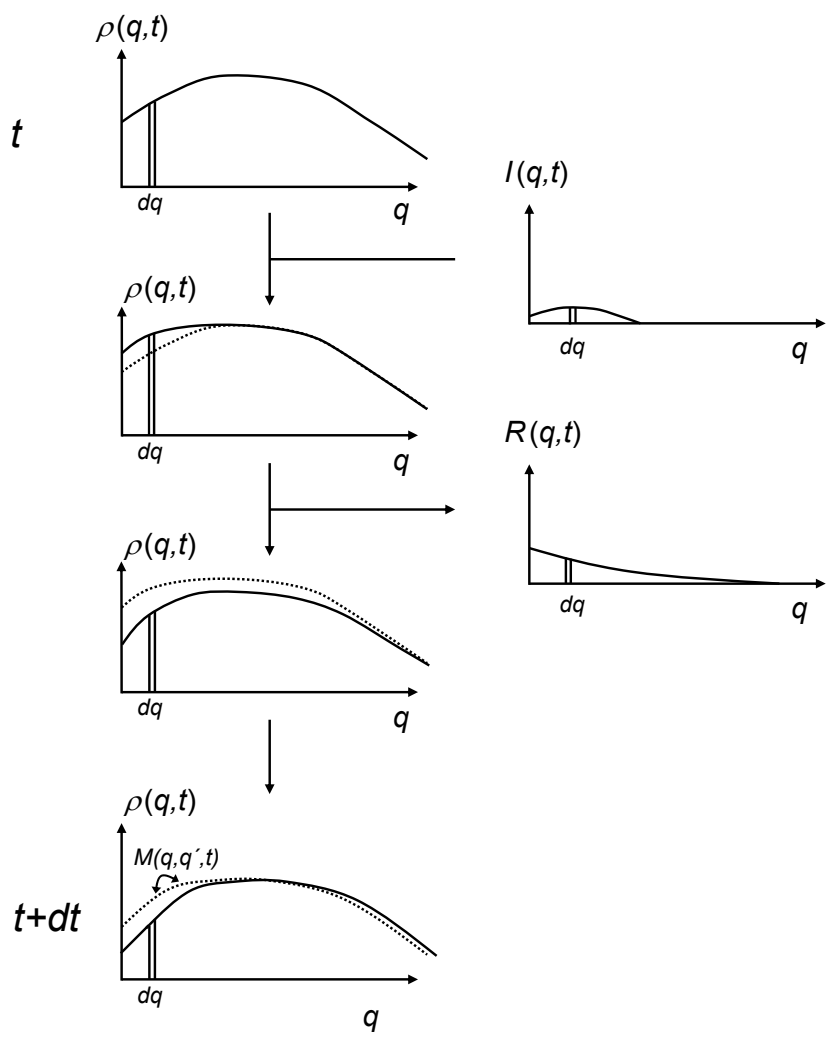

Fig. 1. Changes to the quality distribution of the model in Eq. (2) during a time step. The distribution $\rho(q, t)$ occurring at time $t$ receives carbon from inputs in the form of the distributions $I(q, t)$ and loses carbon due to respiration in the form of the distribution $R(q, t)$. The distribution is then modified by changes in quality or movement of material from quality $q$ to $q^{\prime}, M\left(q, q^{\prime}, t\right)$.

The initial quality distributions $\rho(q, 0)=\rho_{0}(q)$ and two boundary conditions are also needed. Usually, $F\left(q_{1}, t\right)=0$ and $F\left(q_{2}, t\right)=0$ will be appropriate as boundary conditions, i.e. the quality is restricted to the interval $\left[q_{1}, q_{2}\right]$. Now the problem is reduced to choosing functional forms of $k(q, t)$ and $F(q, t)$. If the model is to be useful, these functions should be continuous and relatively simple with a limited number of parameters. Otherwise the parameters will be impossible to estimate and the measurable entity chosen to represent $q$ will not be very useful.

A simple way to describe movement along the $q$-axis is by analogy with either dispersion or convection or a combination of the two, where the dispersion constant, $D(q, t)$, and the convection constant, $v(q, t)$, are dependent on the quality, i.e. $F(q, t)=-D(q, t) \frac{\partial \rho(q, t)}{\partial q}+v(q, t) \rho(q, t)$. This means that Eq. (3) becomes:

$$
\begin{aligned}
\frac{\partial \rho(q, t)}{\partial t} & =I(q, t)-k(q, t) \rho(q, t) \\
& -\frac{\partial\left(D(q, t) \frac{\partial \rho(q, t)}{\partial q}\right)}{\partial q}+\frac{\partial v(q, t) \rho(q, t)}{\partial q}
\end{aligned}
$$

or:

$$
\begin{aligned}
\frac{\partial \rho(q, t)}{\partial t} & =I(q, t)-k(q, t) \rho(q, t)-D(q, t) \frac{\partial^{2} \rho(q, t)}{\partial q^{2}} \\
& +\left(v(q, t)-\frac{\partial D(q, t)}{\partial q}\right) \frac{\partial \rho(q, t)}{\partial q}+\frac{\partial v(q, t)}{\partial q} \rho(q, t)
\end{aligned}
$$

In those cases where $k(q, t), D(q, t)$, and $v(q, t)$ do not depend on the amount of SOC of a specific quality $\rho(q, t)$, but only on the quality $q$, Eq. (5) is linear in $\rho(q, t)$ and the principle of superposition applies. We can then solve the equation for the input of material with a single quality, $I(q)=i_{0} \delta\left(q-q_{0}\right)$ and follow how this is transmitted through the system. This can considerably simplify the interpretation of the properties of the equation. More complex inputs, consisting of a mixture of qualities, are obtained simply by summation of the individual inputs.

In labeling experiments or experiments with changes from vegetation with different photosynthetic systems $\left(\mathrm{C}_{4}\right.$ and $\mathrm{C}_{3}$ ), the effects of isotopic fractionation during decomposition can be negligible. Assuming no isotopic fractionation, the processes described by $k(q, t), D(q, t)$ and $v(q, t)$ will be the same for all isotopes and Eq. (5) can be modified to describe the distribution of an isotope of $\mathrm{C}, \rho^{*}(q, t)$ :

$$
\begin{aligned}
\frac{\partial \rho^{*}(q, t)}{\partial t} & =I^{*}(q, t)-k(q, t) \rho^{*}(q, t)-D(q, t) \frac{\partial^{2} \rho^{*}(q, t)}{\partial q^{2}} \\
& +\left(v(q, t)-\frac{\partial D(q, t)}{\partial q}\right) \frac{\partial \rho^{*}(q, t)}{\partial q}+\frac{\partial v(q, t) \rho^{*}(q, t)}{\partial q}
\end{aligned}
$$

where $I^{*}(q, t)$ is the input distribution of the isotope in question. Such equations for different isotopes can then be combined to produce equations for the isotope ratios; see Poage and Feng (2004) for an application to depth profiles. However, there is in principle no problem with extending Eq. (6) to cover isotopic fractionation, although the estimation of fractionation in the different processes can be difficult (Ågren et al., 1996a).

\subsection{Other simplifying assumptions, modifications, and possible extensions of the model}

Different simplifications of Eq. (2) may be needed from those suggested above. Priming effects (Kuzyakov et al., 2000; Fontaine et al., 2003), where the addition of labile materials stimulates decomposition of recalcitrant materials, and decomposer controlled decomposition (Schimel and Weintraub, 2003; Manzoni and Porporato, 2007) may invalidate the assumption that $R(q, t)$ is proportional to $\rho(q, t)$. This may lead to break-down of the linearity, necessitating the use of numerical methods (see however Neill and Gignoux, 2006) and/or explicit representation of the dynamics of the decomposer community.

In some situations, it may be useful to introduce a theoretical quality variable, $Q$, and model the theoretical distribution of SOM across this variable, $\Theta(Q)$. This is what has been done in continuous quality models so far (Ågren and Bosatta, 1996b). The reason for introducing $Q$ instead of using the measured variable $q$ is to simplify the models. 
This can be achieved if the functions describing respiration as a function of $Q$ and movement along the $Q$ axis are simpler than the corresponding functions depending on $q$. Subsequently, relationships between $Q$ and $q$ or a proxy for $q$ can be pursued. When a theoretical quality variable is introduced, one should also consider the possibility of not aiming at solving the complete model, but instead use it to derive equations for simpler properties like the total SOM, or average qualities etc. (see Ågren and Bosatta, 1996a). It is worth pointing out the analogue with the fundamental equation of quantum mechanics, the wave function, which in principle is unobservable and only projections of it represent observables (momentum, velocity etc.).

The basic model presented in Eq. (2) can be extended in several ways. An obvious extension is to use several different distributions, each corresponding to a SOM fraction. For example, separating microbial biomass from the rest of SOM may be useful, as it has very different characteristics. In that case a transfer function from one distribution to the other is needed and the model becomes similar to that presented by Bosatta and Ågren (1985). Another way to extend the model is to allow multi-dimensional distributions, which may in fact be necessary to obtain an adequate characterization of the SOM. The formalism presented in Eqs. (2) and (3) is easily generalized to accommodate this.

\section{Linking model and measurable distributions}

\subsection{Model application}

An application of Eq. (4) requires the functional form of $k(q, t), D(q, t)$ and $v(q, t)$ to be chosen. In natural ecosystems, the input consists of plant litter and rhizodeposition, and therefore the function $I(q, t)$ can be measured at least on the aboveground part of the input. In the case where $q$ represents size, respiration is expected to decrease as $q$ gets smaller and perhaps some kind of hyperbolic or power function can describe this. The function should intercept $(0,0)$ to allow respiration to approach zero as size approaches zero. In the case where size is used as the quality measure, $D(q, t)$ and $v(q, t)$ must also decrease with $q$ and intercept at $(0,0)$ to completely stop movement along the $q$ axis as soon as size approaches zero. The way in which the functions $D(q, t)$ and $v(q, t)$ approach zero may have large implications (Bosatta and Ågren, 1985).

\subsection{Model parameterization}

When functional forms for the functions $k(q, t), D(q, t)$, and $v(q, t)$ have been chosen, the parameters will have to be estimated. Some parameters can be deduced from theoretical considerations, but most will have to be estimated from field or laboratory experiments. In order to estimate the parameters, we need experiments with different treatments similar to those used for parameterization of the models with SOM pools. Examples of experiments that can be used are those with inputs of organic matter varying either in amount or quality, experiments with treatments with varying tillage intensity or ambient temperature. At the beginning of an experiment, the soil is sampled and a distribution across a quality variable is measured. In cases where storage can be trusted not to have altered the distribution, archived soil samples can be used. At a later stage, after the soil has been subjected to the different treatments, the soil is sampled once again and distributions are measured. It is the changes incurred in these distributions that are used to calibrate the parameters of the functions $k(q, t), D(q, t)$, and $v(q, t)$ using some sort of optimization routine. The fact that the number of parameters in these functions is limited makes this more likely to be achievable. Isotope measurements at different points along the distribution will allow for distributions of the other carbon isotopes or isotope ratios along the quality axis to be concatenated. These will constitute an additional source of data that would be highly valuable for parameter estimation.

To illustrate the process of parameter estimation, we have exemplified it in Fig. 2. In the example, we have constructed hypothetical distributions that might have been obtained if experimental soils had been fractionated according to density. This means that the quality $(q)$ variable is represented by density $(d)$. A soil sampled in the beginning of the experiment (at time 0 years) could give rise to a distribution like that on the left-hand side of Fig. 2. This distribution corresponds to a total amount of SOC of $2.5 \%$. At a later stage (at time 200 years), after the soil has been subjected to a treatment with input or a treatment without input of organic matter, it is sampled once again and distributions are measured, giving rise to the distributions on the right-hand side of Fig. 2. The distribution for the soil without any addition of organic matter corresponds to a total SOC content of $1.9 \%$ while the one receiving an input corresponds to a content of $2.5 \%$. From Fig. 2, it can be seen that in the soil that received no input, the organic matter has been reduced and is shifted towards higher densities. The soil that received an input of light organic matter has developed a peak of light organic matter, unlike the soil receiving no inputs. The distribution of the input can be measured and is also indicated in Fig. 2. In this model application, we chose to describe decay of organic matter as a linearly decreasing function from the lowest measured density $d_{\min }$ (the upper boundary) to 0 at the highest measured density $d_{\max }$ (upper boundary). Thus, $k(d, t)=k_{d \min }-\frac{k_{d \min }}{d_{\max }-d_{\min }}\left(d-d_{\min }\right)$ where $k_{d \min }$ is the decay rate of organic matter of density $d_{\min }$. Similarly, convection was assumed to decrease linearly with density i.e. $v(d, t)=v_{d \min }-\frac{v_{d \min }}{d_{\max }-d_{\min }}\left(d-d_{\min }\right)$, where $v_{d \min }$ is the decay rate of organic matter of density $d_{\min }$. Dispersion was assumed to be constant, i.e. $D(d, t)=D$. Thus we end up with the parameters $d_{\min }, d_{\max }, k_{d \min }, v_{d \min }$, and $D$, which have to be estimated. We set $d_{\min }=0.8 \mathrm{~g} \mathrm{~cm}^{-3}$ and $d_{\max }=2.7 \mathrm{~g} \mathrm{~cm}^{-3}$ and constructed an initial distribution $\rho(d, 0)$ corresponding to the observed distribution at time 0 , 


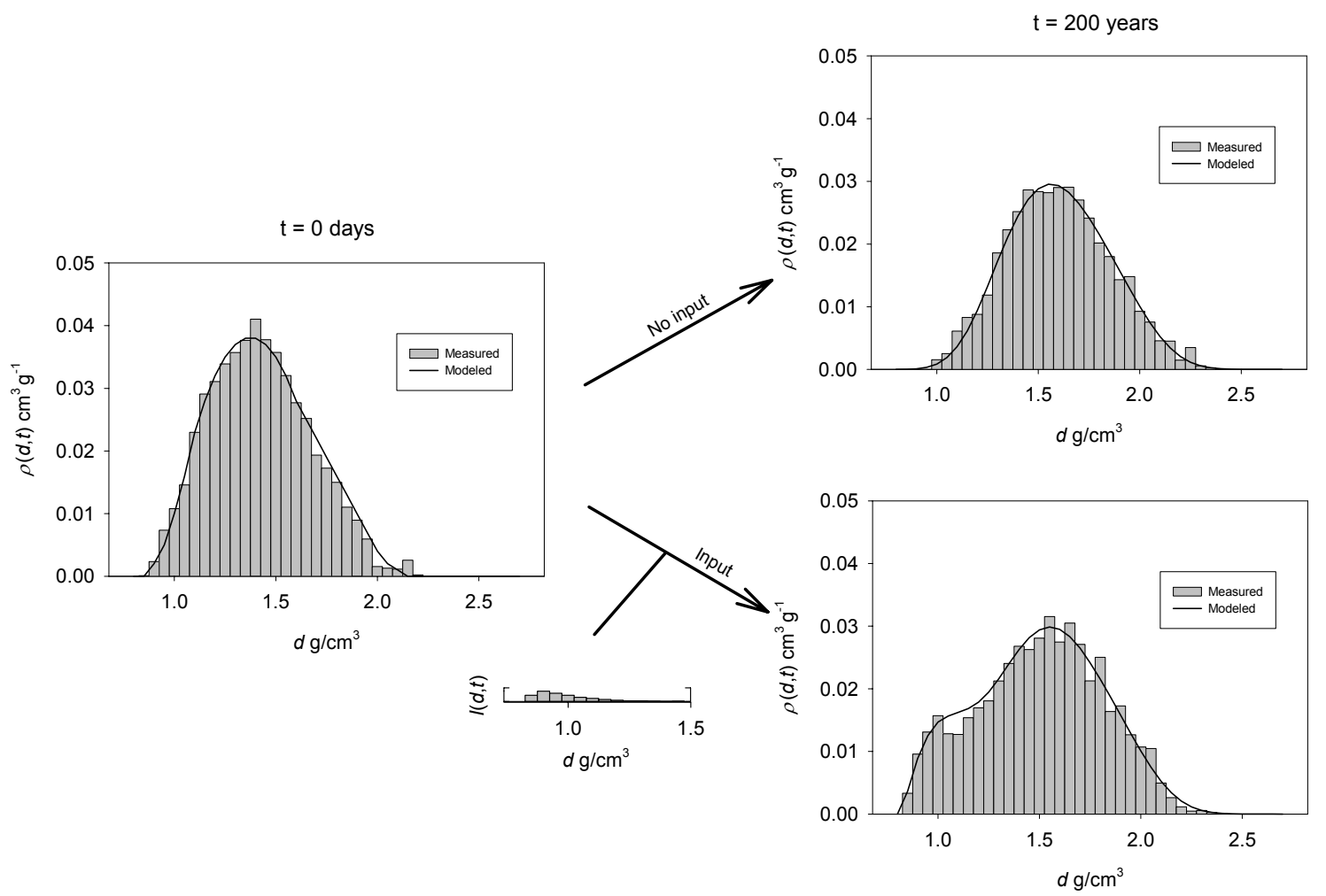

Fig. 2. Constructed example of a model application where a density $(d)$ distribution of SOC is measured on a soil at time 0 years $($ left) and again after 200 years of treatment with or without inputs of organic matter (right). A continuous distribution model is used to describe the of the distribution, and the parameters of the model are optimized to make the distribution fit the observed data (see text for details).

as shown on the left-hand side of Fig. 2, and used Eq. (4) to simulate the change in the distribution over time. Subsequently, we used an optimization routine to find the parameters that resulted in the least sum of squares between the observed and the simulated distributions at time 200 years. The fit of the model after optimization of the parameters is shown on the right-hand side of Fig. 2. The estimated parameters were $k_{d \min }=0.0022$ year $^{-1}, v_{d \min }=0.00127 \mathrm{~g} \mathrm{~cm}^{-3}$ year $^{-1}$ and $D=4.3 \times 10^{-5} \mathrm{~g}^{2} \mathrm{~cm}^{-6}$ year $^{-1}$.

When the choice of measured quality variable makes the simplifying assumptions inappropriate, the more general Eq. (2) may have to be applied. In these cases, $M\left(q, q^{\prime}, t\right)$ and $R(q, t)$ can be complicated functions, and it may be advantageous to use a model introducing a theoretical quality variable, $Q$. Subsequently a proxy for $Q$ is measured and a relationship between the proxy and $Q$ can be estimated through multivariate calibrations (Martens and Naes, 1989). First, the theoretical distribution is established by model fitting to experimental data with different treatments. This gives rise to theoretical distributions across the theoretical quality variable, $\Theta(Q)$. The multivariate calibrations are used to establish a relationship between the $i$ proxy measurements, $p_{i}$, and the theoretical distribution, $\Theta\left(Q_{j}\right)=f\left(p_{i}\right)$. Another possibility is to attempt to predict other properties of the theoretical distribution such as the average quality (i.e. $\left.\bar{Q}=\int Q \Theta(Q, t) d Q / \int \Theta(Q, t) d Q\right)$. However, the multivariate approach requires data from experiments with many different treatments influencing the distributions.

\section{Difference between continuous distributions and fractions}

As carbon and isotopes of carbon can only be measured on a finite sample, a continuous quality distribution of SOC can only be measured by concatenating or merging the finite samples into a distribution. Therefore, measuring a distribution may be viewed as measuring a large number of fractions along the same separation axis, and one might ask what the difference is between measuring fractions and measuring a continuous distribution. This difference arises in terms of both model formulation and requirement for the measurements. The requirement for the measurements is illustrated in Fig. 3. If there is an underlying continuous distribution, then the resolution of the measurements should be so small that the measured distribution approaches the underlying continuum. This is hardly possible with two or three fractions, especially if more or less arbitrary demarcations are made between the fractions or model pools. As we do not know the underlying distribution there is no way 
a

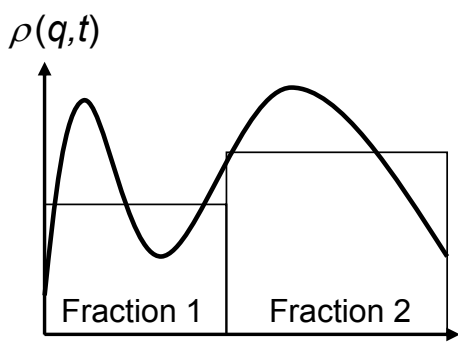

$q$ b

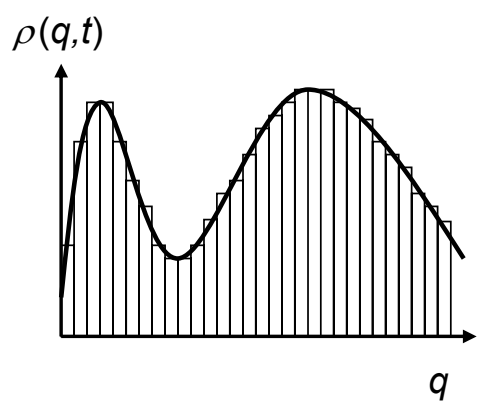

Fig. 3. Illustration of the way in which an underlying continuous distribution is approximated by concatenating a large number of measurements along the axis of measurement. In (a) the underlying distribution is fractionated into two arbitrary fractions that are difficult to relate to the underlying distribution, whereas in (b) the number of fractions has been increased so that the distribution approaches the underlying continuous distribution.

to ensure that the resolution of the measured distribution is actually fine enough to approach the underlying continuous distribution with the desired certainty. However, a requirement that must be fulfilled is that measurements next to each other have values closer to each other than measurements farther away from each other. This means that the distribution can be viewed as continuous and that it is independent of the more or less arbitrary choices of demarcations between the fractions. Another requirement could be that changing the demarcations between the different fractions constituting the distribution or increasing the number of fractions does not markedly change the distribution. The measured continuous SOM quality distributions provide much information about the underlying distribution that should be valuable not only for model development, but also for direct interpretations. Once the underlying distribution has been revealed and possible peaks have been found and identified, it may again be possible to measure a smaller number of fractions where the demarcation between them is determined by the underlying continuum.

The important difference in model formulation can be seen from Eq. (3), where a single function $F(q, t)$ is used to describe the movement of SOM along the $q$ axis, and a single function $k(q, t)$ is used to describe respiration. If we are measuring a continuous distribution, these functions are also more likely to be continuous. This means that these processes can be described by a very limited number of parameters. In contrast, an equivalent multi-compartment formulation would require a large number of compartments and an immense number of parameters to describe these processes from all of the compartments. Thus, the requirement that the functions $F(q, t)$ and $k(q, t)$ are continuous, considerably constrains the shape of functions, whereas for the multicompartment formulation even large differences in parameter combinations will result in nearly equally good fits between data and model (Hyvönen et al., 2005). This means that the resulting parameter combinations are unlikely to have a meaningful biological interpretation. The reduced number of parameters and large number of measurements used for model parameterization of the continuous quality distributions mean that the number of parameter combinations that will allow the model to fit the experimental data is reduced. This is likely to increase the possibility of meaningful interpretations of the parameters and the validity outside the range of conditions tested in the experiments.

\section{Measuring continuous quality distributions of SOM}

Theoretically, the methods used to fractionate SOM into a small number of fractions can be modified by increasing the number of fractions to constitute a virtual continuum. Often, however, this will result in too laborious a method and therefore the application of continuous quality distribution models involves developing new fractionation methods and employing new technologies that are based on similar principles. Fractionation methods can be divided into physical, chemical and biological fractionation methods, and we adopt the same categories here.

Isotope techniques including measurements of isotope ratios in experiments with vegetation changes between $\mathrm{C}_{4}$ and $\mathrm{C}_{3}$ plants, natural abundance of ${ }^{14} \mathrm{C}$ and isotope labeling experiments can be used to determine the dynamics of the different SOM fractions (Saggar et al., 1996; Balesdent and Mariotti, 1996; Bernaux et al., 1998; Bruun et al., 2004, 2005a). In a similar way, measuring isotope ratios along the quality distributions of SOM from similar experiments will undoubtedly greatly help interpretations and model development of continuous quality distribution models of SOM. This requires the isotopes to be measured with sufficient frequency along the quality axis to produce a distribution of the other isotopes or the isotope ratio. 


\subsection{Physical fractionation methods}

\subsubsection{Particle size}

Fractionation according to particle size is based on the fact that mineral particles of different sizes are also of different mineralogical origin and composition and therefore interact with SOM in different ways (Christensen, 1992). The sand fraction which is dominated by quartz only exhibits weak interactions with SOM. This provides different degrees of protection from microbial degradation. The surface area per mass of soil is much larger for the small clay particles and therefore these small particles provide a large surface area for sorption of SOM, which is considered an important stabilizing mechanism (Guggenberger and Kaiser, 2003; Kleber et al., 2007). However, there is no definitive threshold between large and small particles and the transition from quartz to clay minerals is more likely to be continuous than discrete.

Methods used to separate SOM according to particle sizes include sieving and sedimentation and more advanced fractionation methods after dispersion treatments such as treatment by ultrasonic vibrations or application of a chemical dispersant (Christensen, 1992). However, in their extensive review von Lützow et al. (2007) found very variable estimates of turnover times for SOM in different fractions. The lack of an unequivocal relationship between particle size and turnover time may be resolved by separating a size continuum to resolve the distribution better, but may also require separation according to other quality variables as well.

A range of methods has been used to separate colloids according to size (Buffle and Leppard, 1995; Kretzschmar et al., 1999). Some of these methods can be adapted to continuous size distributions of SOM in clay and silt fractions of soils. Measurement of the whole range of SOM size distribution relevant for SOM models requires application of a combination of these methods in different size ranges.

Sieves can be used to measure the size distribution of particles larger than $20-40 \mu \mathrm{m}$, depending on the soil type. However, most carbon is present in smaller sized fractions (Christensen, 1992). In theory, the resolution can always be improved by including more sieve sizes, but the number will be limited in practice. Filtration and ultrafiltration can be used to isolate smaller-sized particles and have been used to separate aquatic colloids in the range $1 \mathrm{~nm}$ to $100 \mu \mathrm{m}$ (Buffle and Leppard, 1995). To avoid artifacts, especially colloid interactions with the membrane and colloid coagulation at the membrane surface, tangential flow filtration can be used to reduce the last artifact.

Sedimentation in water by gravity, centrifugation or ultracentrifugation can be used on smaller particle sizes, but it suffers from the problem that it separates on the basis of both size and density. Sedimentation has been performed by repeatedly suspending soil particles in a water column and waiting for a specific time (calculated according to Stokes law) before removing the upper part of the column (Chris- tensen, 1992). Obtaining a distribution of sufficient resolution probably requires application of new techniques.

Split flow thin cell (SPLITT) fractionation is a technique developed to separate mixtures of materials into fractions of homogeneous materials (Giddings, 1985) and it has already been employed for SOM fractions (Kiem et al., 2002). Size exclusion chromatography and capillary hydrodynamic fractionation (DosRamos and Silebi, 1990) can generally only be used to fractionate particles smaller than $0.1 \mu \mathrm{m}$ without serious artifacts. A very promising technique to separate on the basis of particle size, is field flow fractionation (FFF) (Fraunhofer and Winter, 2004). This technique employs a flat channel through which a carrier liquid is pumped, establishing a parabolic laminar flow profile. The sample is propelled through this channel while a physical field is applied across it, making the particles accumulate on one flank of the channel. Small particles undergo faster Brownian motions and can therefore diffuse against the physical field to where the laminar flow is faster and are thus eluded faster. Several physical fields can be applied across the membrane, giving rise to different sub-techniques. The most important sub-techniques in connection with colloids are sedimentation FFF, where the channel is rotated in a centrifuge, and flow FFF, where a cross-flow is established through permeable channel walls. The technique has been applied to study colloid transport in soils (Ranville et al., 2005), but there seems to be great potential for using the technique on the clay fractions after removing the larger fractions by SPLITT fractionation or some other method.

\subsubsection{Density}

Density fractionation most often consists of separating SOM from heavy and light fractions (Christensen, 1992). The heavy fraction is assumed to consist of organomineral complexes and the SOM of this fraction is assumed to be stabilized by interaction with the mineral phase. The light fraction is assumed to be free of mineral associations and is therefore more susceptible to microbial decay. More complicated fractionation schemes with more density fractions and with density fractionation in combination with other fractionation methods has also been employed (Shaymukhametov et al., 1984; Dalal and Mayer, 1986; Six et al., 2000; Baisden et al., 2002; Sollins et al., 2006). In reviewing the literature, Christensen (1992) recognized that the bonding strengths between SOM and mineral particles varies continuously. Therefore, there does not seem to be a specific density at which mineral associated organic matter is separated from free organic matter. Rather, the ash content, which indicates the presence of mineral soil, seems to increase as density increases, displaying a continuum rather than a fixed cutoff.

The usual method employed to fractionate soil according to density is centrifugation of the sample in a heavy density liquid, to obtain fractions heavier and lighter than the density of the liquid (Christensen, 1992). In recent years, 
polytungstate has been the preferred substance. This can be generalized by using a range of different densities to obtain a distribution with the desired resolution i.e. a sequential density fractionation. Sequential density fractionation has been carried out before with up to eight different densities (Baisden et al., 2002; Sollins et al., 2006, 2009). Separating into eight or more densities is a very tedious procedure and a potentially more powerful approach is to use density gradient centrifugation (DGC). DGC has not been widely used for this purpose, but is being applied routinely for separating microorganisms from soil or other media (Lindahl and Bakken, 1995; Stevens and Jaykus, 2004). After centrifugation in a density gradient a density distribution of particles will have settled in the gradient and samples can be taken out at different positions for determination of $\mathrm{C}$ content and isotope ratios.

\subsubsection{Aggregate size}

SOM seems to degrade more slowly within microaggregates (Six et al., 2002). This has been ascribed to protection involving a number of mechanisms, including seclusion from microbes (van Veen and Kuikman, 1990), reduced oxygen diffusion (Sexstone et al., 1985; Vor et al., 2003), and prevention of microbial predation within aggregates (England et al., 1993). Small aggregates (i.e. microaggregates) seem to offer better protection than larger aggregates. A distribution of aggregate sizes can be obtained by applying either sieving or sedimentation without a preceding dispersion treatment. For the separation of aggregates into a virtual continuum of different sizes, the SPLITT technique described earlier may be applicable. The separation of aggregates is complicated by the fact that a hierarchy of aggregates seems to exist, where smaller first order aggregates are found within larger second order aggregates, which again are collected into larger third order aggregates (Tisdall and Oades, 1982; Oades and Waters, 1991).

\subsubsection{Association with iron oxides}

Iron oxides provide a large surface area in many soils and a strong bonding with SOM by ligand exchange, providing protection against microbial decay (Torn et al., 1997; von Lützow et al., 2007). This means that the amount and crystallinity of iron oxides influence the turnover of the SOM associated with these. Some studies have indicated that clay fractions of intermediate magnetic susceptibility are the most stable (Shang and Tiessen, 1997) while other studies have indicated that the fraction of highest magnetic susceptibility was most stable (Shang and Tiessen, 2000). As the transition from SOM with a low degree of association with iron oxides to SOM with a high degree of association, or from particles with low magnetic susceptibility to high, is likely to be continuous, separating a continuous distribution also appears to be relevant.
Particles of different magnetic susceptibility can be separated using high-gradient magnetic separation (Shang and Tiessen, 1997). In this technique a soil suspension is passed through tubes fitted with stainless steel wool placed in a magnetic field. Material of a high magnetic susceptibility is trapped while the less susceptible material passes through the tubes. By gradually increasing the magnetic field density, it should be possible to separate a virtual continuum of particles of different magnetic susceptibility. Despite promising results, the number of studies using high-gradient magnetic separation is still limited and restricted to tropical soils (von Lützow et al., 2007). Therefore separation into a virtual continuum using this technique could prove interesting.

\subsubsection{Surface charge}

SOM adsorbed on soil particles changes the charge of the particles (Tipping and Cooke, 1982; Saito et al., 2004). Whether resistant SOM adsorbed on the surfaces changes the surface charge more or less than more labile SOM is unknown. However, as the functional groups on the surface of the SOM change as it decomposes, the effect on surface charge is also likely to change. Therefore, it may be worthwhile attempting to separate soil particles according to surface charge to obtain a quality distribution of SOM. Electrophoresis is a technique where an electrical field is applied across a cell and the particles start moving according to their electrophoretic mobility, which is related to zeta potential and surface charge (Hunter, 1981). The technique has been used to separate soil clays according to electrophoretic mobility (e.g. Arshad et al., 1971).

\subsection{Chemical fractionation methods}

Chemical fractionation methods involve some kind of chemical treatment that is applied to hydrolyze or oxidize labile organic matter that is more susceptible to the treatment. These methods can be generalized by applying successively higher concentrations or successively longer treatment times. We suggest that fractionation methods using different concentrations and allowing the process to attain steady-state before the measurements are carried out is better than methods employing different treatment times for the following reason. Under the non steady-state conditions the labile SOM will supposedly be removed faster than more resistant SOM. However, since steady-state has not been attained, not all the labile material will have been removed and a small part of the resistant SOM will also be affected right from the beginning of the treatment.

\subsubsection{Chemical oxidation}

A range of different chemical treatments (e.g. $\mathrm{H}_{2} \mathrm{O}_{2}$, $\mathrm{Na}_{2} \mathrm{~S}_{2} \mathrm{O}_{8}$ and $\mathrm{NaOCl}$ ) has been adopted to remove labile SOM from soil leaving behind a more resistant fraction 
(Mikutta et al., 2005). Different kinds of chemical oxidation methods have also been proposed to isolate black carbon (Schmidt et al., 2001; Simpson and Hatcher, 2004), which is believed to be resistant to biodegradation (Bruun et al., 2008a). Several studies have found the fractions left behind after oxidation to be of higher radiocarbon ages than those removed (Kleber et al., 2005; Eusterhues et al., 2005; Helfrich et al., 2007). However, attempts to verify that the fraction left behind changes in response to organic matter inputs and other aspects of management history are scarce and not very successful (Balesdent, 1996; Plante et al., 2004; Bruun et al., 2008b). This may mean that the chemical oxidation agents do not fractionate the soil in a meaningful way in terms of SOM turnover, but it may also reflect the fact that a stable fraction cannot be resolved by separating two fractions with different susceptibility to oxidation, but requires a continuous distribution of oxidizability to be measured.

Continuous distributions could be achieved by modifying oxidation methods using different concentrations of oxidants or oxidation times, with the results concatenated into a distribution. An example of the latter can be found in Plante et al. (2004), who oxidized soils assumed to have different amounts of resistant $\mathrm{SOM}$ using $\mathrm{H}_{2} \mathrm{O}_{2}$, extracted aliquots by syringe after different oxidation times, and analyzed these for organic carbon. The resulting distribution seemed to differ between the soils, with soils containing more labile carbon losing carbon more rapidly during the first $3-8 \mathrm{~h}$.

\subsubsection{UV oxidation}

UV oxidation was initially proposed as a method to isolate an inactive fraction of SOM because the oxidizing agents produced by the light were believed to be unable to penetrate into aggregates (Skjemstad et al., 1993). Later, UV oxidation was developed into a method to reduce SOM fractions other than black carbon before determination of the black carbon content (Skjemstad et al., 1999). UV oxidation offers opportunities for measuring quality distributions by varying either the effect of the UV lamp or the oxidation time. Skjemstad et al. (1993) observed the disappearance of organic C during the first eight hours of oxidation and found that $\mathrm{C}$ disappeared faster in some soils than others. In contrast, Bruun et al. (2008b) observed faster removal of old SOM than litter, possibly because of the litter containing lignin, which is resistant to UV oxidation, and thus did not find any evidence that old SOM is more protected from UV oxidation. The method is rather laborious and fractionating the complete quality continuum may therefore be difficult unless modifications of the procedure are developed. For example, it may be possible to sub-sample after different oxidation times or measure $\mathrm{CO}_{2}$ evolution and the isotopic composition of the $\mathrm{CO}_{2}$ evolved.

\subsubsection{Thermal analysis}

In thermal analysis a soil sample is heated according to a heating program, usually with a constant heating rate. A distribution, known as a thermogram, can be produced by measuring the weight loss as a function of temperature. The gases evolved can also be analyzed by different kinds of spectroscopic methods (David, 1975; Schulten, 1993; Plante et al., 2009). Either method offers an easy way to measure the amount of carbon or mass lost at different temperatures producing a thermogram. The thermograms often exhibit different peaks for labile and more resistant SOM (Kristensen, 1990; Schulten and Leinweber, 1999; Siewert, 2004; LopezCapel et al., 2005b; Bruun et al., 2008b). Thermal treatments have also been used to isolate black carbon from soil (Gustafsson et al., 1997, 2001; Gelinas et al., 2001). If a strong relationship between the thermogram and the degradability of SOM can be established, the use of a thermogram to characterize a continuous distribution of SOM in a distributional model would be a straight-forward procedure. However, significant challenges in the interpretation and quantification of thermal data still remain (Plante et al., 2009)

Lopez-Capel et al. (2005a) analyzed the gases evolved during thermal treatment by coupling a thermo-gravimetric system with an isotope ratio mass spectrometer. This appears to be a very powerful setup, because it allows measurement of isotope ratios along the quality distribution of SOM, which can be used to trace carbon inputs labeled with isotopes in the thermograms.

Mass spectrometry of the pyrolysis products can be used to construct thermograms with the total ion intensity, but can also be used to make thermograms of compound classes such as carbohydrates, lignin monomers, lignin dimers, alkyl aromatics, lipids and $\mathrm{N}$-containing compounds, thus giving rise to a different distribution for each compound class (Schulten and Leinweber, 1999, 2000). Application of the proposed distributional models to these distributions therefore also requires a model with several distributions and assumptions about their formation.

\subsubsection{Hydrolysis}

Acid hydrolysis is one of the most widely used methods for isolation of an inactive fraction of SOM (e.g. Laevitt et al., 1996; Trumbore et al., 1996). Hot $6 \mathrm{M} \mathrm{HCl}$ is usually refluxed for $18 \mathrm{~h}$ and the supernatant is removed after centrifugation. The remaining amount of $\mathrm{C}$ is then measured. A distribution of hydrolyzability can be produced by employing different concentrations of acid or different reaction times. As large numbers of treatments are required to get sufficient resolution in the measured distribution, samples of the supernatant can be taken instead and analyzed for dissolved SOM by different methodologies. Acid hydrolysis has been widely applied to isolate an inactive fraction and seems to isolate old SOM (Martel and Paul, 1974; Laevitt et al., 1996; Paul et 
al., 1997). However, as for chemical oxidation, the fraction of hydrolyzable $\mathrm{C}$ seems to be relatively independent of the management in field trials (Balesdent, 1996; Plante et al., 2006). Some of these problems may be solved by measuring a continuous distribution instead of just using a predetermined acid concentration or treatment time.

\subsection{Biological fractionation methods}

The advantage of biological fractionation methods is that they are directly related to the mechanisms responsible for decomposition in the soil. Soil incubation under constant, favorable conditions has been used to isolate labile and more resistant fractions of SOM (Paul et al., 2006). This can be generalized to measure a continuous quality distribution by continuously measuring $\mathrm{CO}_{2}$ evolution. However, as for the chemical treatments of different durations, the incubations will not start by removing only the labile material but will also remove resistant SOM, albeit more slowly, right from the beginning. If a whole continuum of SOM quality exists, the data produced in the incubations are unlikely to be sufficient to reveal the quality distribution (Bruun and Luxhøi, 2006). Furthermore, by the very nature of resistant SOM, incubations cannot be used to measure the distribution covering the SOM of lower quality. Another problem with soil incubation is that the soil is often disturbed during sampling, so the observed flux of $\mathrm{CO}_{2}$ is due to mineralization of organic matter liberated from protection rather than a labile fraction occurring in the soil.

A possible alternative would be to use enzymatic digestion. A range of enzymes designed to dissolve different organic compounds very fast at high temperatures has been developed. This type of enzymatic digestion could also be used to estimate a quality distribution by repeated measurements of the amount of dissolved SOM. To our knowledge, enzymatic digestion has not been used previously to fractionate SOM, so the method requires development and its usefulness needs to be proved. A potential problem with this approach is that lignolytic enzymes seem to be unable to digest all lignin in fresh plant material, even though it is not considered to be highly resistant to decay (Kiem and Kögel-Knabner, 2003). As the addition of enzymes also results in the addition of organic matter, these techniques would require some form of labeling experiment to distinguish between $\mathrm{C}$ from enzymes and SOM.

\subsection{Proxies for soil organic matter quality distributions}

As described above an alternative to measuring the distributions directly is to measure some proxy for soil organic matter quality distributions and relate this to a theoretical quality distribution by multivariate calibrations. A range of spectroscopic methods including py-GC/MS, near-infrared spectroscopy (NIR), mid-infrared spectroscopy (MIR), nuclear magnetic resonance spectroscopy (NMR), and others have the potential to generate spectra that are related to the quality of SOM. In addition amino acid composition has already shown potential as a proxy for SOM quality in marine sediments.

\subsubsection{Nuclear magnetic resonance spectroscopy (NMR)}

NMR measures shifts in the frequency at which atomic nuclei resonate relative to a reference compound when subjected to a magnetic field. The chemical shift is influenced by the electron clouds around the nucleus and therefore provides information about the chemical environment in which it exists (Veeman, 1997). The chemical composition of SOM has been characterized by solid state ${ }^{13} \mathrm{C}$ NMR (e.g. Skjemstad et al., 1997; Kögel-Knabner, 2002). The spectrum that is obtained by ${ }^{13} \mathrm{C}$ NMR is generally split into four main regions (carbonyl, aromatic, $\mathrm{O}$ alkyl, and alkyl) and the area of a given region is proportional to the amount of that group in the sample. During decomposition, the spectra of SOM change in characteristic ways (Skjemstad et al., 1997), with alkyl carbon being lost initially.

In the case of NMR spectra, the measured quality variable across which the carbon distribution is measured is the chemical shift. A specific chemical shift corresponds to a $\mathrm{C}$ atom in a specific chemical constellation and therefore should also correspond to a specific respiration rate and a specific rate of transformation to other chemical constellations.

\subsubsection{Near-infrared spectroscopy (NIR)}

The detailed chemical structure of SOM can also be revealed by near-infrared spectroscopy (NIR), which measures absorbance or reflectance of electromagnetic radiation in the near infrared range. This is related to vibrational and rotational movements of important biochemical functional groups such as - $\mathrm{CH},-\mathrm{OH}$, and -NH chemical bonds (Shenk et al., 2001). During the course of decomposition, the NIR spectrum is modified in a regular way (Joffre et al., 1992; Gillon et al., 1999) and the rate of decomposition can be predicted from the NIR spectrum (Bruun et al., 2005b; Thomsen et al., 2009). However, no monotonous relationship is likely to exist between the frequency at which light is absorbed and resistance to biodegradation. However, using multivariate analysis, these modifications in spectra have been correlated with the change in the average theoretical quality of the carbon compounds in a model for litter decomposition (Joffre et al., 2001).

\subsubsection{Amino acid composition}

The composition of amino acids in marine sediments seems to be altered in a regular fashion upon degradation (Dauwe and Middelburg, 1998). This has been used to develop a degradation index based on amino acid composition which has been related directly measured decomposition constants (Dauwe et al., 1999; Vandewiele et al., 2009). This indicates 
that, amino acid composition can be used as a proxy for organic matter quality in marine sediments, but the methodology still needs to be explored in soils.

\subsection{Measuring several distributions}

As suggested in the model formulation, it may be useful to determine quality distributions for several fractions. For example, it could be useful to measure the quality of the microbial biomass separately because of the very different role of this fraction of SOM. However, there is no obvious way to separate microbial biomass from the rest of the SOM. More generally, the approach of separating the SOM into fractions with different distributions suffers from the same shortcomings as the models of measurable fractions, i.e. there will usually not be any well-defined thresholds between the fractions, making the choice of a threshold more or less arbitrary. Therefore, it is doubtful that this can be made operational.

\subsection{Distributions in more dimensions}

Measuring distributions in several dimensions is probably necessary because a single quality variable as defined above is not likely to capture all the different mechanisms that will affect the decomposition of SOM. Separating according to more than one quality variable allows us to take different stabilizing mechanisms into account and understand their importance. Essentially, what is required to apply continuous quality SOM models in two dimensions is two different ways of measuring quality, say $q_{1}$ and $q_{2}$. For example, a distribution of particle density could first be made, which would result in a number of samples with different densities. The samples along this distribution could then be separated by thermal analysis. From the review above we know that particle density is related to the degree of association with mineral particles, while resistance to high temperatures is related to chemical recalcitrance. Such a combination of fractionation methods therefore provides a much better resolution of the measurements and thus a better basis for model development and validation, but also provides information on the effect of several stabilization mechanisms and their contribution to the overall stability of the organic matter in the soil.

\section{Conclusions}

We argue that to improve our SOM models, continuous quality distribution models should be developed in concert with fractionation methods measuring continuous quality SOM distributions. Compared with the conventional coupling between pool models and discrete fractions, the approach promises a reduced number of model parameters. In combination with the increased detail of measurements, this means that the number of parameter combinations that allow the model to fit the experimental data is reduced. This will increase the possibility for meaningful interpretations of the parameters and the validity of the models outside the range of conditions tested by experimentation. Therefore, the approach offers new opportunities for improving SOM models in terms of predictive power, as well as our conceptual and mechanistic understanding of SOM dynamics. The measured continuous quality SOM distributions should also be useful for direct interpretations, while information about the underlying continuous distribution may help develop useful discrete fractionation schemes.

There are a number of potential methodologies that can be employed to measure continuous quality distributions of SOM. Based on the evidence available, we believe that fractionation according to size and density and thermal treatment are the most promising methods for fractionation of continuous quality SOM distributions. Developing the fractionation methods will be a major task. New fractionation techniques will have to be developed, and the methods can be combined in a large number of different ways, resulting in distributions in more than one dimension. Therefore, this task requires the efforts of a large research community. We hope that the current paper will generate interest in the approach and entice enough researchers to explore the possibilities and prove its merits.

Acknowledgements. The study was financially supported by the project ContQ, funded by Gluds Legat and by a grant from the Danish Agricultural and Veterinary Research Council (Grant no. 23-03-0102). Thanks are due to Joanne Smith and Margit von Lützow for their useful comments on a draft of the manuscript.

Edited by: J. Middelburg

\section{References}

Ågren, G. and Bosatta, E.: Theoretical ecosystem ecology: understanding element cycles, Cambridge University Press, Cambridge, 1996a.

Ågren, G. I. and Bosatta, E.: Quality: a bridge between theory and experiment in soil organic matter studies, Oikos, 76, 522-528, 1996b.

Ågren, G. I., Bosatta, E., and Balesdent, J.: Isotope discrimination during decomposition of organic matter: a theoretical analysis, Soil Sci. Soc. Am. J., 60, 1121-1126, 1996a.

Ågren, G. I., Kirschbaum, M. U. F., Johnson, D. W., and Bosatta, E.: Ecosystem physiology - Soil organic matter, in: Global change: Effects on coniferous forests and grasslands, edited by: Breymeyer, A. I., Hall, D. O., Melillo, J. M., and Ågren, G. I., John Wiley \& Sons Ltd, Chichester, 1996b.

Arah, A. R. M. and Gaunt, J. L.: Questionable assumptions in the current soil organic matter transformation models, in: Sustainable management of soil organic matter, edited by: Rees, R. M., Ball, B. C., Campbell, C. D., and Watson, C. A., CABI publishing, Oxon, 83-89, 2001.

Arshad, M. A., Starnaud, R. J., and Huang, P. M.: Characterization of electrophoretic separates of soil clays, Soil Sci., 112, 46-52, 1971. 
Baisden, W. T. and Amundson, R.: An analytical approach to ecosystem biogeochemistry modeling, Ecol. Appl., 13, 649-663, 2003.

Baisden, W. T., Amundson, R., Cook, A. C., and Brenner, D. L.: Turnover and storage of $\mathrm{C}$ and $\mathrm{N}$ in five density fractions from California annual grassland surface soils, Global Biogeochem. Cy., 16, 1117, doi:10.1029/2001GB001822, 2002.

Balesdent, J.: The significance of organic separates to carbon dynamics and its modelling in some cultivated soils, Eur. J. Soil Sci., 47, 485-493, 1996.

Balesdent, J. and Mariotti, A.: Measurement of soil organic matter turnover using ${ }^{13} \mathrm{C}$ natural abundance, in: Mass spectrometry of soils, edited by: Boutton, T. W. and Yamasaki, S. I., Marcel Dekker, New York, 83-111, 1996.

Bernaux, M., Cerri, C. C., Neill, C., and de Moraes, J. F. L.: The use of stable carbon isotopes for estimation soil organic matter turnover rates, Geoderma, 82, 43-58, 1998.

Bird, M., Santrùcková, H., Lloyd, J., and Lawson, E.: The isotopic composition of soil organic carbon on a north-south transect in western Canada, Eur. J. Soil Sci., 53, 393-403, 2002.

Bosatta, E. and Ågren, G. I.: Theoretical analysis of decomposition of heterogeneous substrates, Soil Biol. Biochem., 17, 601-610, 1985.

Bosatta, E. and Ågren, G. I.: Dynamics of carbon and nitrogen in the organic matter of the soil: a generic theory, Am. Nat., 138, 227-245, 1991

Bosatta, E. and Ågren, G. I.: Exact solutions to the continuousquality equation for soil organic matter turnover, J. Theor. Biol., 224, 97-105, 2003.

Boudreau, B. P.: A kinetic model for microbic organic matter decomposition in marine sediments, FEMS Microbiol. Ecol., 102, 1-14, 1992.

Bruun, S., Jensen, E. S., and Jensen, L. S.: Microbial mineralization and assimilation of black carbon: Dependency on degree of thermal alteration, Org. Geochem., 39, 839-845, 2008 a.

Bruun, S. and Luxhøi, J.: Letter to the editor on "Can incubations be used to measure meaningful pools of soil organic matter?", Soil Sci. Soc. Am. J., 70, 2164, 2006.

Bruun, S., Six, J., and Jensen, L. S.: Estimating vital statistics and age distributions of measurable soil organic carbon fractions based on their pathway of formation and radiocarbon content, J. Theor. Biol., 230, 241-250, 2004.

Bruun, S., Six, J., Paustian, K., and Jensen, L. S.: Estimating turnover of measurable soil organic carbon fractions based on radiocarbon measurements, Radiocarbon, 47, 99-113, 2005a.

Bruun, S., Stenberg, B., Breland, T. A., Gudmundsson, J., Henriksen, T., Jensen, L. S., Korsaeth, A., Luxhøi, J., Palmason, F., Pedersen, A., and Salo, T.: Empirical predictions of plant material $\mathrm{C}$ and $\mathrm{N}$ mineralization patterns from near infrared spectroscopy, stepwise chemical digestion and $\mathrm{C} / \mathrm{N}$ ratios, Soil Biol. Biochem., 37, 2283-2296, 2005b.

Bruun, S., Thomsen, I. K., Christensen, B. T., and Jensen, L. S.: In search of stable soil organic carbon fractions: a comparison of methods applied to soils labelled with ${ }^{14} \mathrm{C}$ for 40 days or 40 years, Eur. J. Soil Sci., 59, 247-256, 2008b.

Buffle, J. and Leppard, G. G.: Characterization of aquatic colloids and macromolecules .2. Key role of physical structures on analytical results, Environ. Sci. Technol., 29, 2176-2184, 1995.

Buyanovsky, G. A., Aslam, M., and Wagner, G. H.: Carbon turnover in soil physical fractions, Soil Sci. Soc. Am. J., 58, 1167-1173, 1994

Carpenter, S. R.: Decay of heterogenous detritus: a general model, J. Theor. Biol., 89, 539-547, 1981.

Christensen, B. T.: Physical fractionation of soil and organic matter in primary particle size and density separates, Adv. Soil Sci., 20, 1-90, 1992.

Christensen, B. T.: Matching measurable soil organic matter fractions with conceptual pools in simulation models: Revision of model structure, in: Evaluation of soil organic matter models, using existing long term datasets, edited by: Powlson, D. S., Smith, P., and Smith, J. U., Springer, Berlin, 143-159, 1996.

Christensen, B. T.: Physical fractionation of soil and structural and functional complexity in organic matter turnover, Eur. J. Soil Sci., 52, 345-353, 2001.

Coleman, K. and Jenkinson, D. S.: Roth C-26.3 - A model for the turnover of carbon in soil, in: Evaluation of soil organic matter models, using existing long-term datasets, edited by: Powlson, D. S., Smith, P., and Smith, J. U., Springer, Berlin, 237-246, 1996.

Dalal, R. C. and Mayer, R. J.: Long-term trends in fertility of soils under continuous cultivation and cereal cropping in Southern Queensland .IV. Loss of organic carbon from different density fractions, Aust. J. Soil Res., 24, 301-309, 1986.

Dauwe, B. and Middelburg, J. J.: Amino acids and hexosamines as indicators of organic matter degradation state in North Sea sediments, Limnol. Oceanogr., 43, 782-798, 1998.

Dauwe, B., Middelburg, J. J., Herman, P. M. J., and Heip, C. H. R.: Linking diagenetic alteration of amino acids and bulk organic matter reactivity, Limnol. Oceanogr., 44, 1809-1814, 1999.

David, C.: Thermal degradation of polymers, in: Degradation of polymers, edited by: Bamford, C. H. and Tipper, C. F. H., Elsevier, Amsterdam, 1-173, 1975.

DosRamos, J. G. and Silebi, C. A.: The determination of particle size distribution of submicrometer particles by capillary hydrodynamic fractionation (CHDF), J. Colloid. Interf. Sci., 135, 165$177,1990$.

Elliott, E. T., Paustian, K., and Frey, S. D.: Modeling the measurable or measuring the modelable: A hierarchical approach to isolating meaningful soil organic matter fractionations, in: Evaluation of soil organic matter models, using existing long term datasets, edited by: Powlson, D. S., Smith, P., and Smith, J. U., Springer, Berlin, 161-179, 1996.

England, L. S., Lee, H., and Trevors, J. T.: Bacterial survival in soil - Effect of clays and protozoa, Soil Biol. Biochem., 25, 525-531, 1993.

Eusterhues, K., Rumpel, C., and Kögel-Knabner, I.: Stabilization of soil organic matter isolated via oxidative degradation, Org. Geochem., 36, 1567-1575, 2005.

Fontaine, S., Mariotti, A., and Abbadie, L.: The priming effect of organic matter: a question of microbial competition?, Soil Biol. Biochem., 35, 837-843, 2003.

Fraunhofer, W. and Winter, G.: The use of asymmetrical flow fieldflow fractionation in pharmaceutics and biopharmaceutics, Eur. J. Pharm. Biopharm., 58, 369-383, 2004.

Gelinas, Y., Prentice, K. M., Baldock, J. A., and Hedges, J. I.: An improved thermal oxidation method for the quantification of soot/graphitic black carbon in sediments and soils, Environ. Sci. Technol., 35, 3519-3525, 2001. 
Giddings, J. C.: A system based on split-flow lateral transport thin (Splitt) separation cells for rapid and continuous particle fractionation, Sep. Sci. Technol., 20, 749-768, 1985.

Gillon, D., Joffre, R., and Ibrahima, A.: Can litter decomposability be predicted by near infrared reflectance spectroscopy?, Ecology, 80, 175-186, 1999.

Goldberg, E. D.: Black carbon in the environment, John Wiley and Sons, New York, 1985.

Guggenberger, G. and Kaiser, K.: Dissolved organic matter in soil: challenging the paradigm of sorptive preservation, Geoderma, 113, 293-310, 2003.

Gustafsson, O., Bucheli, T. D., Kukulska, Z., Andersson, M., Largeau, C., Rouzaud, J. N., Reddy, C. M., and Eglinton, T. I.: Evaluation of a protocol for the quantification of black carbon in sediments, Global Biogeochem. Cy., 15, 881-890, 2001.

Gustafsson, O., Haghseta, F., Chan, C., MacFarlane, J., and Gschwend, P. M.: Quantification of the dilute sedimentary soot phase: Implications for PAH speciation and bioavailability, Environ. Sci. Technol., 31, 203-209, 1997.

Hassink, J.: Decomposition rate constants of size and density fractions of soil organic matter, Soil Sci. Soc. Am. J., 59, 1631-1635, 1995.

Hassink, J. and Dalenberg, J. W.: Decomposition and transfer of plant residue ${ }^{14} \mathrm{C}$ between size and density fractions in soil, Plant Soil, 179, 159-169, 1996.

Helfrich, M., Flessa, H., Mikutta, R., Dreves, A., and Ludwig, B.: Comparison of chemical fractionation methods for isolating stable soil organic carbon pools, Eur. J. Soil Sci., 58, 1316-1329, 2007.

Hunter, R. J.: Zeta potential in colloid science, Academic Press, London, 1981.

Hyvönen, R., Ågren, G. I., and Dalias, P.: Analysing temperature response of decomposition of organic matter, Glob. Change Biol., 11, 770-778, 2005.

Joffre, R., Ågren, G. I., Gillon, D., and Bosatta, E.: Organic matter quality in ecological studies: theory meets experiment, Oikos, 93, 451-458, 2001.

Joffre, R., Gillon, D., Dardenne, P., Agneessens, R., and Biston, R.: The use of near-infrared reflectance spectroscopy in litter decomposition studies, Ann. Sci. For., 49, 481-488, 1992.

Kiem, R., Knicker, H., and Kögel-Knabner, I.: Refractory organic carbon in particle-size fractions of arable soils I: distribution of refractory carbon between the size fractions, Org. Geochem., 33, 1683-1697, 2002.

Kiem, R. and Kögel-Knabner, I.: Contribution of lignin and polysaccharides to the refractory carbon pool in C-depleted arable soils, Soil Biol. Biochem., 35, 101-118, 2003.

Kleber, M., Mikutta, R., Torn, M. S., and Jahn, R.: Poorly crystalline mineral phases protect organic matter in acid subsoil horizons, Eur. J. Soil Sci., 56, 717-725, 2005.

Kleber, M., Sollins, P., and Sutton, R.: A conceptual model of organo-mineral interactions in soils: self-assembly of organic molecular fragments into zonal structures on mineral surfaces, Biogeochemistry, 85, 9-24, 2007.

Kögel-Knabner, I.: The macromolecular organic composition of plant and microbial residues as inputs to soil organic matter, Soil Biol. Biochem., 34, 139-162, 2002.

Kretzschmar, R., Borkovec, M., Grolimund, D., and Elimelech, M.: Mobile subsurface colloids and their role in contaminant trans- port, Adv. Agron., 66, 121-193, 1999.

Kristensen, E.: Characterization of biogenic organic-matter by stepwise thermogravimetry (Stg), Biogeochem., 9, 135-159, 1990.

Kuzyakov, Y., Friedel, J. K., and Stahr, K.: Review of mechanisms and quantification of priming effects, Soil Biol. Biochem., 32, 1485-1498, 2000.

Laevitt, S. W., Follet, R. F., and Paul, E. A.: Estimation of slow- and fast cycling soil organic carbon pools from 6N HCL hydrolysis, Radiocarbon, 38, 231-239, 1996.

Lindahl, V. and Bakken, L. R.: Evaluation of methods for extraction of bacteria from soil, FEMS Microbiol. Ecol., 16, 135-142, 1995.

Lopez-Capel, E., Bol, R., and Manning, D. A. C.: Application of simultaneous thermal analysis mass spectrometry and stable carbon isotope analysis in a carbon sequestration study, Rapid Commun. Mass Spectrom., 19, 3192-3198, 2005a.

Lopez-Capel, E., Sohi, S. P., Gaunt, J. L., and Manning, D. A. C.: Use of thermogravimetry-differential scanning calorimetry to characterize modelable soil organic matter fractions, Soil Sci. Soc. Am. J., 69, 136-140, 2005b.

Magid, J., Gorissen, A., and Giller, K.: In search of the elusive "active" fraction of soil organic matter: three size-density fractionation methods for tracing the fate of homogeneously ${ }^{14} \mathrm{C}$-labeled plant materials, Soil Biol. Biochem., 28, 89-99, 1996.

Manzoni, S. and Porporato, A.: Theoretical analysis of nonlinearities and feedbacks in soil carbon and nitrogen cycles, Soil Biol. Biochem., 39, 1542-1556, 2007.

Martel, Y. A. and Paul, E. A.: The use of radiocarbon dating of organic matter in the study of soil genesis, Soil Sci. Soc. Am. Proc., 38, 501-506, 1974.

Martens, H. and Naes, T.: Multivariate calibration, John Wiley and Sons, Chichester, 1989.

Masiello, C. A.: New directions in black carbon organic geochemistry, Mar. Chem., 92, 201-213, 2004.

McGill, W. B.: Review and classification of ten soil organic matter (SOM) models, in: Evaluation of soil organic matter models, using existing long term datasets, edited by: Powlson, D. S., Smith, P., and Smith, J. U., Springer, Berlin, 111-132, 1996.

Mikutta, R., Kleber, M., Kaiser, K., and Jahn, R.: Review: Organic matter removal from soils using hydrogen peroxide, sodium hypochlorite, and disodium peroxodisulfate, Soil Sci. Soc. Am. J., 69, 120-135, 2005.

Neill, C. and Gignoux, J.: Soil organic matter decomposition driven by microbial growth: A simple model for a complex network of interactions, Soil Biol. Biochem., 38, 803-811, 2006.

Oades, J. M. and Waters, A. G.: Aggregate hierarchy in soils, Aust. J. Soil Res., 29, 815-828, 1991.

Parton, W. J., Schimel, D. S., Cole, C. V., and Ojima, D. S.: Analysis of factors controlling soil organic matter levels in Great Plains grasslands, Soil Sci. Soc. Am. J., 51, 1173-1179, 1987.

Paul, E. A., Follett, R. F., Leavitt, S. W., Halvorson, A., Peterson, G. A., and Lyon, D. J.: Radiocarbon dating for determination of soil organic matter pool sizes and dynamics, Soil Sci. Soc. Am. J., 61, 1058-1067, 1997.

Paul, E. A., Morris, S. J., Conant, R. T., and Plante, A. F.: Does the acid hydrolysis-incubation method measure meaningful soil organic carbon pools?, Soil Sci. Soc. Am. J., 70, 1023-1035, 2006.

Plante, A. F., Chenu, C., Balabane, M., Mariotti, A., and Righi, D.: 
Peroxide oxidation of clay-associated organic matter in a cultivation chronosequence, Eur. J. Soil Sci., 55, 471-478, 2004.

Plante, A. F., Conant, R. T., Paul, E. A., Paustian, K., and Six, J.: Acid hydrolysis of easily dispersed and microaggregate-derived silt- and clay-sized fractions to isolate resistant soil organic matter, Eur. J. Soil Sci., 57, 456-467, 2006.

Plante, A. F., Fernández, J. M., and Leifeld, J.: Application of thermal analysis techniques in soil science, Geoderma, 153, 1-10, 2009.

Poage, M. A. and Feng, X. H.: A theoretical analysis of steady state $\delta^{13} \mathrm{C}$ profiles of soil organic matter, Global Biogeochem. Cy., 18, GB2016, doi:10.1029/2003GB002195,, 2004.

Ranville, J. F., Chittleborough, D. J., and Beckett, R.: Particle-size and element distributions of soil colloids: Implications for colloid transport, Soil Sci. Soc. Am. J., 69, 1173-1184, 2005.

Reichstein, M., Ågren, G., and Fontaine, S.: Is there a theoretical limit to soil carbon storage in old-growth forests?, in: OldGrowth forests, edited by: Wirth, G., Gleixner, G., and Heimann, M., Springer, Berlin, 267-281, 2009.

Saggar, S., Parshotam, A., Sparling, G. P., Feltham, C. W., and Hart, P. B. S.: ${ }^{14}$ C-labelled ryegrass turnover and residence times in soils varying in clay content and mineralogy, Soil Biol. Biochem., 28, 1677-1686, 1996.

Saito, T., Koopal, L. K., van Riemsdijk, W. H., Nagasaki, S., and Tanaka, S.: Adsorption of humic acid on goethite: Isotherms, charge adjustments, and potential profiles, Langmuir, 20, 689700, 2004

Schimel, J. P. and Weintraub, M. N.: The implications of exoenzyme activity on microbial carbon and nitrogen limitation in soil: a theoretical model, Soil Biol. Biochem., 35, 549-563, 2003.

Schmidt, M. W. I., Skjemstad, J. O., Czimczik, C. I., Glaser, B., Prentice, K. M., Gelinas, Y., and Kuhlbusch, T. A. J.: Comparative analysis of black carbon in soils, Global Biogeochem. Cy., 15, 163-167, 2001.

Schulten, H. R.: Analytical Pyrolysis of Humic Substances and Soils - Geochemical, Agricultural and Ecological Consequences, J. Anal. Appl. Pyrol., 25, 97-122, 1993.

Schulten, H. R. and Leinweber, P.: Thermal stability and composition of mineral-bound organic matter in density fractions of soil, Eur. J. Soil Sci., 50, 237-248, 1999.

Schulten, H. R. and Leinweber, P.: New insights into organicmineral particles: composition, properties and models of molecular structure, Biol. Fert. Soils, 30, 399-432, 2000.

Sexstone, A. J., Revsbech, N. P., Parkin, T. B., and Tiedje, J. M.: Direct measurement of oxygen profiles and denitrification rates in soil aggregates, Soil Sci. Soc. Am. J., 49, 645-651, 1985.

Shang, C. and Tiessen, H.: Organic matter lability in a tropical oxisol: Evidence from shifting cultivation, chemical oxidation, particle size, density, and magnetic fractionations, Soil Sci., 162, 795-807, 1997.

Shang, C. and Tiessen, H.: Carbon turnover and carbon-13 natural abundance in organo-mineral fractions of a tropical dry forest soil under cultivation, Soil Sci. Soc. Am. J., 64, 2149-2155, 2000 .

Shaymukhametov, M. S., Titova, N. A., Travnikova, L. S., and Labenets, Y. M.: Use of physical fractionation methods to characterize soil organic matter, Soviet Soil Science, 16, 117-128, 1984.

Shenk, J. S., Workman, J. J., and Westerhaus, M. O.: Application of NIR spectroscopy to agricultural products, in: Handbook of Near-Infrared Analysis, edited by: Burns, D. A. and Ciurczak, E. W., Marcel Dekker, Inc., 419-473, 2001.

Siewert, C.: Rapid screening of soil properties using thermogravimetry, Soil Sci. Soc. Am. J., 68, 1656-1661, 2004.

Simpson, M. J. and Hatcher, P. G.: Determination of black carbon in natural organic matter by chemical oxidation and solid-state 13C nuclear magnetic resonance spectroscopy, Org. Geochem., 35, 923-935, 2004.

Six, J., Conant, R. T., Paul, E. A., and Paustian, K.: Stabilization mechanisms of soil organic matter: Implications for C-saturation of soils, Plant Soil, 241, 155-176, 2002.

Six, J., Elliott, E. T., Paustian, K., and Doran, J. W.: Aggregation and soil organic matter accumulation in cultivated and native grassland soils, Soil Sci. Soc. Am. J., 62, 1367-1377, 1998.

Six, J., Merckx, R., Kimpe, K., Paustian, K., and Elliott, E. T.: A re-evaluation of the enriched labile soil organic matter fraction, Eur. J. Soil Sci., 51, 283-293, 2000.

Skjemstad, J. O., Clarke, P., Colchin, A., and Oades, J. M.: Characterization of soil organic matter by solid-state ${ }^{13} \mathrm{C}$ NMR spectroscopy, in: Driven by nature. Plant litter quality and decomposition, edited by: Cadisch, G. and Giller, K. E., CAB International, Wallingford, 3-30, 1997.

Skjemstad, J. O., Janik, L. J., Head, M. J., and McClure, S. G.: High energy ultraviolet photooxidation: a novel technique for studying physically protected organic matter in clay-sized and silt-sized aggregates, J. Soil Sci., 44, 485-499, 1993.

Skjemstad, J. O., Spouncer, L. A., Cowie, B., and Swift, R. S.: Calibration of the Rothhamsted organic turnover model (Roth ver 26.3), using measureable soil organic carbon pools, Aust. J. Soil Res., 42, 79-88, 2004.

Skjemstad, J. O., Taylor, J. A., and Smernik, R. J.: Estimation of charcoal (char) in soils, Comm. Soil Sci. Plant Anal., 30, 2283 2298, 1999.

Smith, J. U., Smith, P., Monaghan, R., and MacDonald, A. J.: When is a measured soil organic matter fraction equivalent to a model pool?, Eur. J. Soil Sci., 53, 405-416, 2002.

Sohi, S. P., Mahieu, N., Arah, J. R. M., Powlson, D. S., Madari, B., and Gaunt, J. L.: A procedure for isolating soil organic matter fractions suitable for modeling, Soil Sci. Soc. Am. J., 65, 11211128, 2001.

Sollins, P., Homann, P., and Caldwell, B. A.: Stabilization and destabilization of soil organic matter: Mechanisms and controls, Geoderma, 74, 65-105, 1996.

Sollins, P., Kramer, M. G., Swanston, C., Lajtha, K., Filley, T., Aufdenkampe, A. K., Wagai, R., and Bowden, R. D.: Sequential density fractionation across soils of contrasting mineralogy: evidence for both microbial- and mineral-controlled soil organic matter stabilization, Biogeochem., 96, 209-231, 2009.

Sollins, P., Swanston, C., Kleber, M., Filley, T., Kramer, M., Crow, S., Caldwell, B. A., Lajtha, K., and Bowden, R.: Organic C and $\mathrm{N}$ stabilization in a forest soil: Evidence from sequential density fractionation, Soil Biol. Biochem., 38, 3313-3324, 2006.

Stevens, K. A. and Jaykus, L. A.: Bacterial separation and concentration from complex sample matrices: A review, Crit. Rev. Microbiol., 30, 7-24, 2004.

Thomsen, I. K., Bruun, S., Jensen, L. S., and Christensen, B. T.: Assessing soil carbon lability by near infrared spectroscopy and $\mathrm{NaOCl}$ oxidation, Soil Biol. Biochem., 41, 2170-2177, 2009. 
Tipping, E. and Cooke, D.: The effects of adsorbed humic substances on the surface charge of goethite (alpha-FeOOH) in fresh waters, Geochim. Cosmochim. Ac., 46, 75-80, 1982.

Tisdall, J. M. and Oades, J. M.: Organic matter and water-stable aggregates in soils, J. Soil Sci., 33, 141-163, 1982.

Torn, M. S., Trumbore, S. E., Chadwick, O. A., Vitousek, P. M., and Hendricks, D. M.: Mineral control of soil organic carbon storage and turnover, Nature, 389, 170-173, 1997.

Trumbore, S. E., Chadwick, O. A., and Amundson, R.: Rapid exchange between soil carbon and atmospheric carbon dioxide driven by temperature change, Science, 272, 393-396, 1996.

Trumbore, S. E. and Zheng, S. H.: Comparison of fractionation methods for soil organic matter ${ }^{14} \mathrm{C}$ analysis, Radiocarbon, 38, 219-229, 1996.

van Veen, J. A. and Kuikman, P. J.: Soil structural aspects of decomposition of organic matter by micro-organisms, Biogeochem., 11, 213-233, 1990.

Vandewiele, S., Cowie, G., Soetaert, K., and Middelburg, J. J.: Amino acid biogeochemistry and organic matter degradation state across the Pakistan margin oxygen minimum zone, DeepSea Res. II, 56, 376-392, 2009.
Veeman, W. S.: Nuclear magnetic resonance, a simple introduction to the principles and applications, Geoderma, 80, 225-242, 1997.

von Lützow, M., Kögel-Knabner, I., Ekschmitt, K., Flessa, H., Guggenberger, G., Matzner, E., and Marschner, B.: SOM fractionation methods: Relevance to functional pools and to stabilization mechanisms, Soil Biol. Biochem., 39, 2183-2207, 2007. von Lützow, M., Kögel-Knabner, I., Ekschmitt, K., Matzner, E., Guggenberger, G., Marschner, B., and Flessa, H.: Stabilization of organic matter in temperate soils: mechanisms and their relevance under different soil conditions - a review, Eur. J. Soil Sci., 57, 426-445, 2006.

Vor, T., Dyckmans, J., Loftfield, N., Beese, F., and Flessa, H.: Aeration effects on $\mathrm{CO}_{2}, \mathrm{~N}_{2} \mathrm{O}$, and $\mathrm{CH}_{4}$ emission and leachate composition of a forest soil, J. Plant Nutr. Soil Sci., 166, 39-45, 2003.

Zimmermann, M., Leifeld, J., Schmidt, M. W. I., Smith, P., and Fuhrer, J.: Measured soil organic matter fractions can be related to pools in the RothC model, Eur. J. Soil Sci., 58, 658-667, 2007. 